\title{
Successful treatment of an impacted lithotripter basket in the common bile duct with intracorporeal electrohydraulic lithotripsy
}
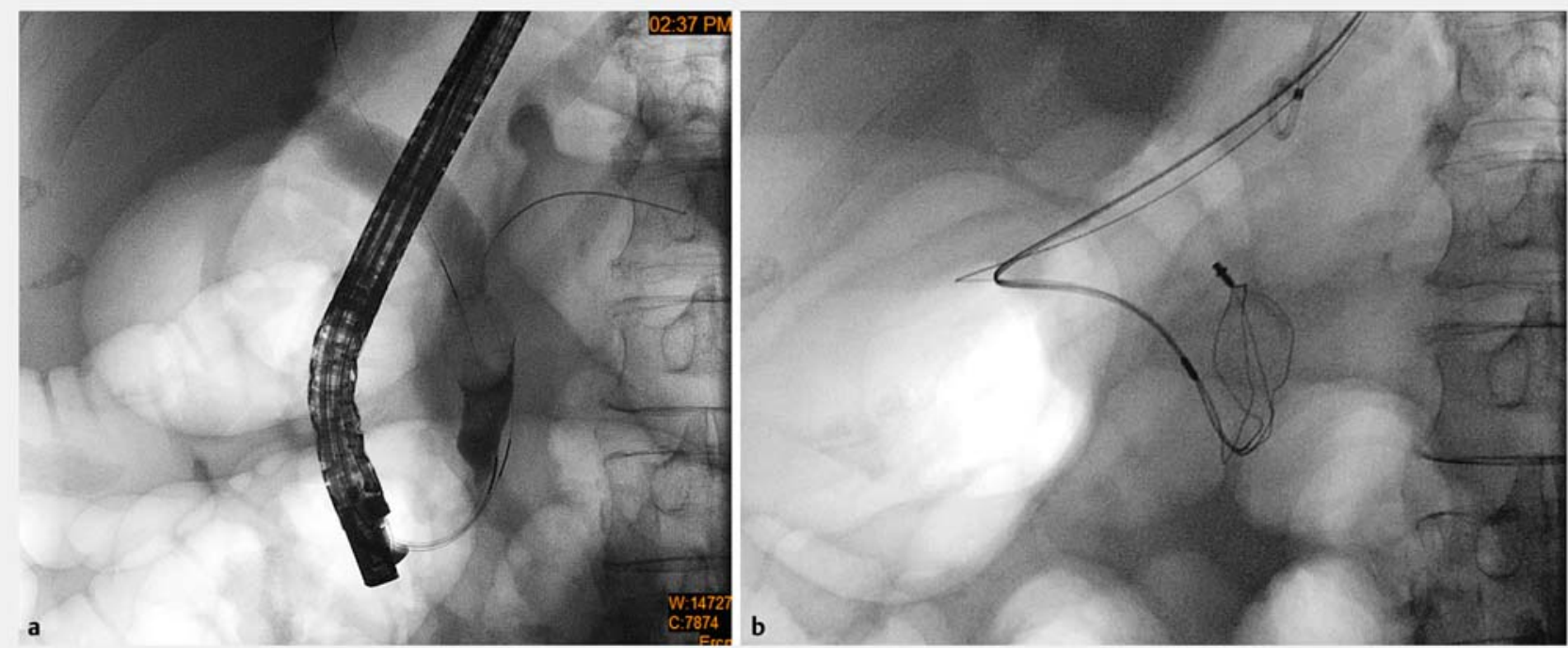

- Fig. 1 Radiographic images during endoscopic retrograde cholangiopancreatography showing: a common bile duct (CBD) dilatation up to $20 \mathrm{~mm}$ on the initial cholangiogram; $\mathbf{b}$ the impacted lithotripter basket in the CBD during attempted extraction following mechanical lithotripsy.

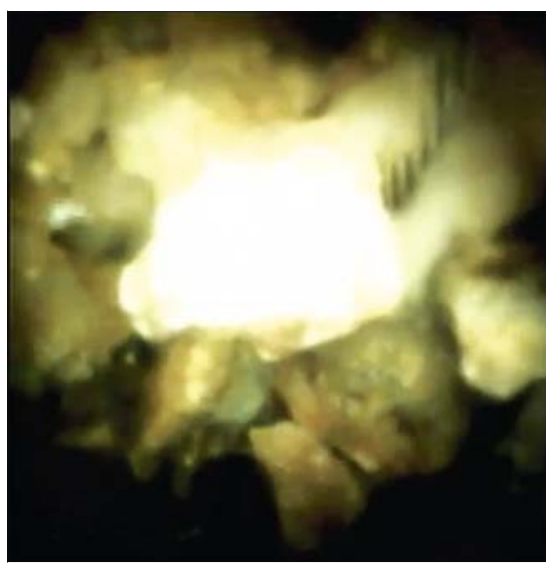

Fig. 2 Cholangioscopic view showing the initial stone burden during electrohydraulic lithotripsy.

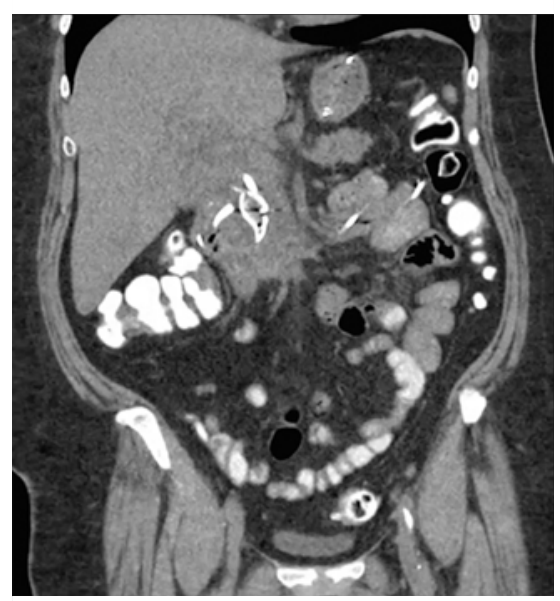

Fig. 3 Computed tomography scan of the abdomen on day 1 showing the impacted basket and retained hardware.
A 62-year-old woman with hypothyroidism and hypertension presented to an outside hospital with abdominal pain. She was found on her initial workup to have choledocholithiasis and was transferred to our institution for endoscopic retrograde cholangiopancreatography (ERCP). The cholangiogram demonstrated common bile duct (CBD) dilatation, with right and left hepatic duct dilatation ( $\triangleright$ Fig. 1 a). When mechanical lithotripsy to break up the stone was attempted,

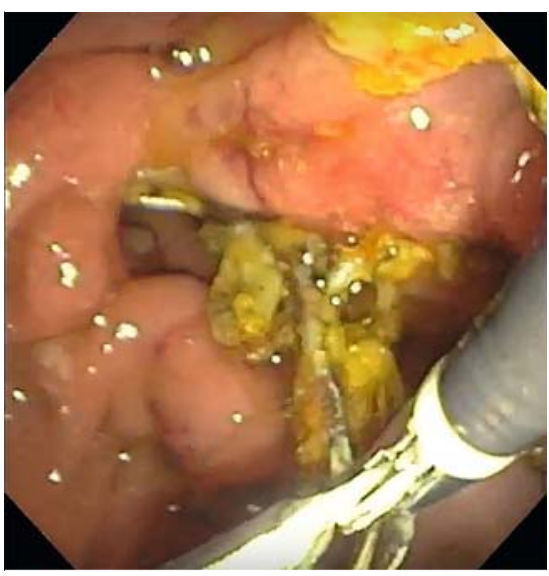

> Fig. 4 Endoscopic view during repeat endoscopic retrograde cholangiopancreatography on day 3 showing extraction of the impacted basket with a rat-toothed forceps.

the stone and basket became impacted in the distal CBD during extraction ( Fig.1b). An emergency lithotripter (Olympus America, Center Valley, Pennsylvania, USA) was used to release the basket from around the stone, but the 


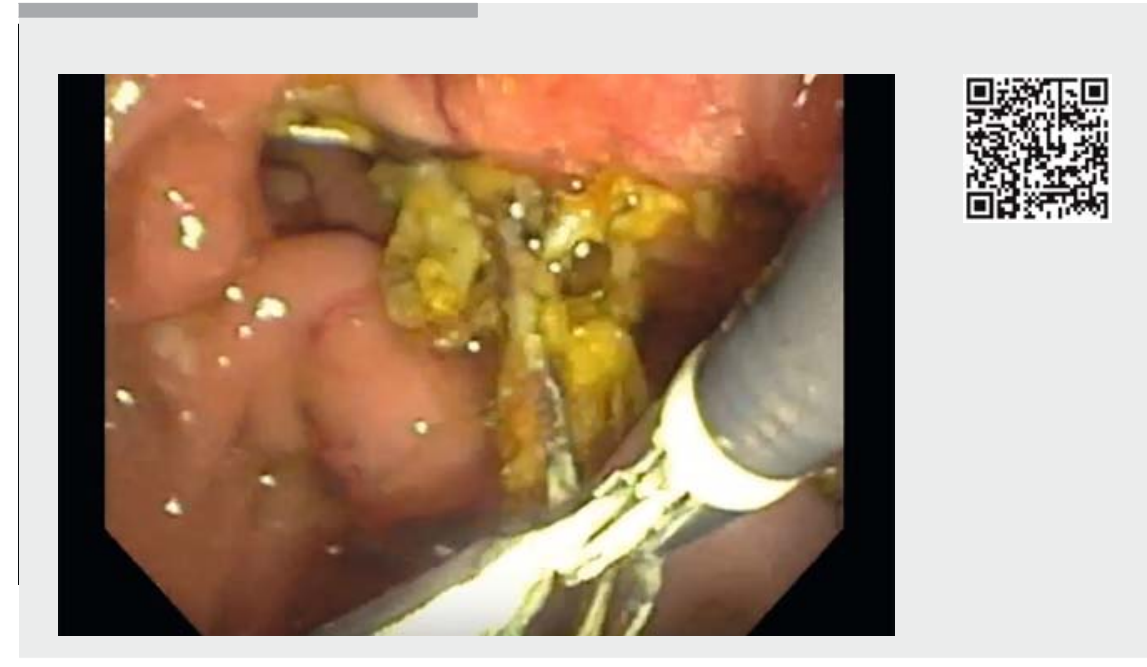

Video 1 Successful treatment of an impacted lithotripter basket and stone in the common bile duct with intracorporeal electrohydraulic lithotripsy.

device broke owing to a mechanical malfunction and the wires of the basket were severed near the handle and sheath. Direct cholangioscopy was then performed with electrohydraulic lithotripsy (EHL) to fragment the stone ( $>$ Fig. 2 ), although further attempts were unsuccessful. A computed tomography (CT) scan of the abdomen after the procedure showed the impacted hardware ( $>$ Fig.3). A multidisciplinary decision was made to repeat ERCP with EHL and attempt removal of the hardware. Direct cholangioscopy was used to perform EHL for over 40 minutes to break up the stone. The basket was then grasped with a rat-toothed forceps and was successfully removed from the CBD ( $\triangleright$ Fig. 4 ; $\triangleright$ Video 1 ). It was then possible to clearly visualize the hilum of the CBD and there was no evidence of retained stone fragments or obvious biliary tract disruption ( $>$ Fig. 5 ).

Impaction of lithotripter baskets and emergency lithotripter malfunction during ERCP are rare occurrences. We are a high-volume advanced endoscopy center and have experienced staff working with us for all procedures. While there is always a risk of user error, we believe this instance was due to a device malfunc- tion. We present a case in which an impacted lithotripter and CBD stone were treated with $\mathrm{EHL}$ resulting in destruction of the retained stone so that the lithotripter basket could then be pulled out.

Endoscopy_UCTN_Code_TTT_1AR_2AH

\section{Competing interests}

Juan Carlos Bucobo is a consultant for Boston Scientific.

The authors

Justine Fenner ${ }^{1}$, Michael P. Croglio' ${ }^{1}$, Demetrios Tzimas ${ }^{2}$, Juan Carlos Bucobo ${ }^{2}$

1 Stony Brook University School of Medicine, Stony Brook, New York, USA

2 Department of Gastroenterology, Stony Brook University Hospital, Stony Brook, New York, USA

Corresponding author

\section{Michael P. Croglio, BS}

22 Brookvale Lane, Lake Grove, NY 11755 ,

USA

microglio@gmail.com

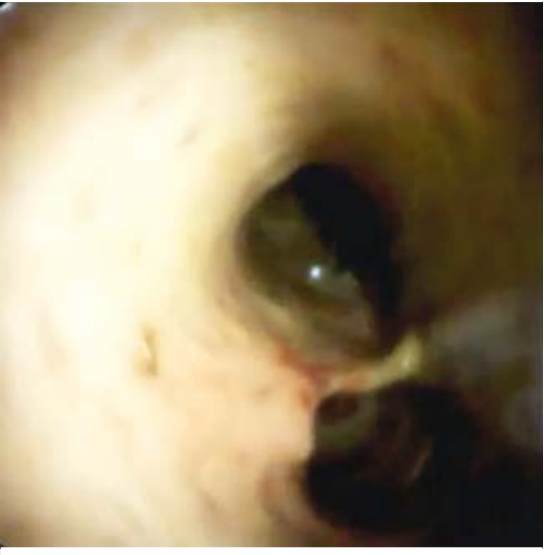

- Fig. 5 Cholangioscopic image showing patency and integrity of the hilum of the common bile duct following successful removal of the retained basket.

\section{Bibliography}

DOI https://doi.org/10.1055/s-0043-124176

Published online: 19.1.2018

Endoscopy 2018; 50: 447-448

(C) Georg Thieme Verlag KG

Stuttgart · New York

ISSN 0013-726X

\section{ENDOSCOPY E-VIDEOS \\ https://eref.thieme.de/e-videos}

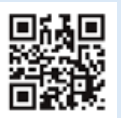

Endoscopy E-Videos is a free access online section, reporting on interesting cases and new techniques in gastroenterological endoscopy. All papers include a high quality video and all contributions are freely accessible online.

This section has its own submission website at

https://mc.manuscriptcentral.com/e-videos 